\title{
A OLIMPÍADA BRASILEIRA DE ROBÓTICA NO ES E SEU POTENCIAL DE TRANSFORMAÇÃO DA SOCIEDADE CAPIXABA
}

Lorena Bacheti Bassani - lorena.bassani@aluno.ufes.br

Universidade Federal do Espírito Santo

Av. Fernando Ferrari, 514, Goiabeiras

29075-910 - Vitória - Espírito Santo

Gabriel Pietroluongo Nascimento - gabriel.nascimento.50@aluno.ufes.br

Universidade Federal do Espírito Santo

Av. Fernando Ferrari, 514, Goiabeiras

29075-910 - Vitória - Espírito Santo

Higor David Oliveira - higor.d.oliveira@aluno.ufes.br

Universidade Federal do Espírito Santo

Av. Fernando Ferrari, 514, Goiabeiras

29075-910 - Vitória - Espírito Santo

André Ferreira - andrefer@ele.ufes.br

Universidade Federal do Espírito Santo

Av. Fernando Ferrari, 514, Goiabeiras

29075-910 - Vitória - Espírito Santo

Resumo: Este artigo trata sobre a OBR (Olimpíada Brasileira de Robótica) como uma ferramenta de mudança da sociedade. Primeiramente, analisando a robótica sob a ótica de auxílio e estímulo ao aluno no domínio dos conceitos necessários para obter um bom desempenho em matérias que, historicamente, são percebidas como mais complexas, como a matemática e a física. Por consequência, também é analisado o mérito da robótica como um apoio ao aluno ingressante na área das engenharias, que possuem uma baixa taxa de aproveitamento em seu ciclo básico decorrente do déficit de domínio dos conceitos base necessários ao aluno. Além disso, a própria estrutura do torneio é dissecada, explorando as interações entre os participantes e as consequências decorrentes obtidas a médio e longo prazo. Também é abordado brevemente o movimento maker e a sua relação com a robótica e com o evento. O histórico da competição e os resultados obtidos são escrutinados, correlacionando o investimento em eventos relacionados à grande área da robótica aos resultados obtidos e listando algumas das conquistas das equipes capixabas em contextos internacionais.

Palavras-chave: Robótica. PBL. Olimpíada.

\section{INTRODUÇÃO}

Um dos principais déficits do aprendizado básico brasileiro são as áreas das ciências exatas, como física e matemática. No ensino clássico, elas são apresentadas de forma massiva 
aos alunos, sobrecarregando-os e desmotivando o interesse em carreiras que necessitem destes conhecimentos. Isso se torna uma barreira ao ingresso do aluno no ensino superior e, mesmo que ele consiga adentrar este novo nível de ensino, mais tarde, novamente ele sentirá dificuldades durante o aprendizado de matérias e de novos conceitos que exigem pleno domínio das matérias do ensino básico (DANTAS FILHO, 2018).

Um dos principais motivos pelo qual a aprendizagem das disciplinas exatas é considerada massiva e extremamente fatigante ao aluno é a falta de estímulos que o método clássico apresenta, dando extremo foco ao conceito e pouco foco nas aplicações (DANTAS FILHO, 2018).

A robótica, quando usada na educação, permite ao estudante tomar conhecimento da tecnologia atual, desenvolver habilidades e competências muito importantes na sua formação pessoal e futura formação profissional (ZILLI, 2004). Isso porque as tecnologias e conceitos aprendidos durante os estudos da robótica são base para as mais diversas engenharias e ciências, além de gerar uma maior consciência das tecnologias que cercam o aluno em sua vida.

A OBR (Olimpíada Brasileira de Robótica) é uma das olimpíadas científicas brasileiras apoiadas pelo CNPq que se utiliza da temática da robótica - tradicionalmente de grande aceitação junto aos jovens - para estimulá-los às carreiras científico-tecnológicas, identificar jovens talentosos, e promover debates e atualizações no processo de ensino-aprendizagem brasileiro. Possui diversas modalidades que procuram adequar-se tanto ao público que nunca viu robótica quanto ao público de escolas que já têm contato com a robótica educacional. A OBR destina-se a todos os alunos de qualquer escola pública ou privada do ensino fundamental, médio ou técnico em todo o território nacional, e é uma iniciativa pública, gratuita e sem fins lucrativos. Para que todo o país seja alcançado, são realizadas as etapas estaduais, onde as equipes campeãs em seus respectivos estados se classificam para competir na etapa nacional.

A OBR trabalha com base em incentivar os alunos de ensino básico a se interessarem por matemática, ciências e tecnologia, através da proposta de um problema do mundo real (uma simulação de resgate), que os alunos devem submeter um protótipo de robô que possa resolver esse problema para avaliação em uma maquete. O formato competitivo e amigável da competição torna-se ainda mais atrativo para as crianças e adolescentes, atraindo cada vez mais equipes participantes a cada ano.

\section{AS DIFICULDADES PARA O INGRESSANTE DA ENGENHARIA}

A educação do ensino médio no Brasil, atualmente, no que diz respeito às ciências básicas, não é suficientemente eficaz para preparar o estudante para a vida universitária nos cursos de engenharia (RODRIGUES, 2012). Alunos dos cursos superiores de engenharia se veem constantemente abaixo do desempenho esperado nas matérias base de seus cursos.

Existe uma falsa noção de que os alunos que ingressam no ensino superior, em especial em cursos da rede pública, já estão preparados para enfrentar os desafios da vida acadêmica. O ensino básico é, dessa forma, tratado como uma forma de "seleção natural” para os alunos aptos. Essa noção traz ainda, por consequência, a ideia de que alunos que apresentem rendimento abaixo do esperado para a graduação tenham, como único problema, a falta de dedicação naquela matéria (BLANDO, 2015).

Mas é possível notar que o problema de desmotivação e despreparo dos alunos vai muito além de apenas falta de interesse e dedicação, sendo estes, muitas vezes, nem mesmo fatores para tal desempenho. Muitos alunos com altos níveis de preocupação e dedicação acadêmica 
demonstram baixos níveis de desempenho, em especial para matérias que exigem base na matemática e nas ciências exatas.

No ano de 2018, o Brasil participou da prova do PISA - Programa Internacional de Avaliação de Estudantes. O PISA é uma pesquisa sobre a educação mundial, divulgada a cada três anos, pela OCDE - Organização para Cooperação e Desenvolvimento Econômico. O Brasil, que participa da pesquisa desde sua primeira edição em 2000, avaliou cerca de 13.000 estudantes e presenciou uma queda da posição 65 para a 70 na disciplina de matemática (MORALES, 2019).

A situação do déficit na formação do nível básico proporciona problemas para relacionar novos assuntos com os antigos, uma vez que estes não foram totalmente compreendidos pelo aluno, e ainda gera confusão para compreensão de novos conhecimentos (LOPES RIPARDO, DE SOUSA OLIVEIRA \& BRANDÃO MENEZES, 2020). Grandes esforços são aplicados nos cursos de graduação para tentar minimizar esse déficit, como exemplo a realização de cursos preparatórios de matemática básica para ingressantes. Porém, estes esforços teriam resultados muito mais proveitosos se aplicados antes do nível de graduação.

Alunos de ensino básico possuem chances de obterem resultados melhores em esforços de nivelamento que alunos de nível superior, pois estão ainda em fase de aprendizagem básica, onde o déficit ainda não lhes causou tantos danos quanto aos alunos de nível superior. Ainda assim, apenas reforçar as técnicas já utilizadas no ensino clássico, que possui foco nos conceitos mais que em suas aplicações, não seria uma solução eficaz.

Neste contexto, iniciativas para incentivar os alunos de ensino fundamental, médio e técnico integrado a resolverem problemas do mundo real, em uma abordagem PBL, mostramse um grande aliado nessa batalha para melhorar o ensino de matérias base das ciências exatas, como física e matemática. O PBL é uma metodologia de ensino e aprendizagem que utiliza problemas para gerar maior interesse, foco e motivação na aprendizagem dos conhecimentos conceituais (DE CAMARGO RIBEIROA, 2008), tendo o aluno como principal ator no processo de aprendizagem. Uma vez que tais métodos proporcionam a oportunidade dos alunos de compreenderem o comportamento de conceitos teóricos na realidade, eles podem perceber, de forma clara, o impacto que suas ações podem fazer na sociedade.

A robótica, por ser uma área multidisciplinar que proporciona uma grande variedade de aplicações no mundo real, tem o potencial de atrair estudantes do ensino básico, revitalizando a educação em ciência, tecnologia, engenharia e matemática (JUNG, 2012).

A educação para engenheiros precisa ser de modo que estes possam atender à evolução constante das necessidades da indústria e da sociedade (PADIR \& CHERNOVA, 2013). Por ser altamente favorável ao ensino utilizando a abordagem PBL, a robótica proporciona não apenas uma motivação para a aprendizagem, mas também muitos conhecimentos que são essenciais para os futuros engenheiros. $\mathrm{E}$ isso pode vir desde muito antes do ingresso no curso de graduação, trabalhando tais habilidades desde o ensino básico.

Dentre as competências adquiridas pelos alunos que desenvolvem projetos na área da robótica, se encontram a perspectiva multidisciplinar; o pensamento crítico e criativo; habilidades de comunicação e trabalho em equipe e a noção de problemas socioeconômicos e ambientais. Dessa forma, a robótica pode ser utilizada para criar a ponte entre o ensino e a prática da engenharia (PADIR \& CHERNOVA, 2013). O incentivo ao desenvolvimento de projetos em robótica desde o ensino básico aumenta as chances do aluno se tornar um profissional de engenharia altamente competente em seu futuro.

É exatamente com essa base que a OBR se apresenta para crianças e adolescentes de todo o Brasil: fornecer um desafio do mundo real, mesmo que com diversas abstrações para 
simplificação e adaptação ao nível dos estudantes, para incentivar a pesquisa e aprendizagem de conceitos através do desenvolvimento de uma solução para tal desafio; proporcionar um ambiente competitivo, cooperativo e incentivador para o aluno demonstrar e debater suas soluções com outros colegas; e, em paralelo, avaliar seu desempenho através de uma prova teórica (etapa teórica).

\section{DA FICÇÃO CIENTÍFICA AO ROBÔ AUTÔNOMO SEGUIDOR DE LINHA}

Os robôs são muito conhecidos como personagens de ficção científica. A ideia de um robô complexo, às vezes, até humanoide a ponto de se disfarçar diante de nossos olhos, se tornou viva no imaginário popular por meio de obras literárias, como "Eu, Robô", de Isaac Asimov, e cinematográficas, como “A.I. - Inteligência Artificial”, de Spielberg. Por mais que isso seja um incentivo, principalmente às crianças, para se aventurarem nas áreas de tecnologia e robótica, ainda se encontram longe da realidade do mercado e do cotidiano da maior parte da sociedade brasileira.

Nas últimas décadas, ocorreu uma ampla gama de desenvolvimentos na robótica. Desde robôs que exploram o espaço, como os Mars Exploration Rovers, desenvolvidos pela NASA a fim de explorar pela primeira vez Marte, até robôs que realizam tarefas cotidianas, como os robôs aspiradores. A automatização de tarefas repetitivas, perigosas ou simplesmente tediosas, sejam elas simples ou complexas, sempre foi um desejo humano (ROSARIO, 2012). Os robôs de navegação e operação autônomas são um grande passo para o desenvolvimento humano, e, com a constante melhoria das ferramentas e tecnologias disponíveis, a sociedade pode, finalmente, ver tal desejo se realizar.

Mas ainda há um longo caminho entre ter as tecnologias disponíveis para implementar esses robôs e realizá-los de forma concreta. Para isso, é necessário despertar o interesse em crianças e adolescentes para que possam, desde novos, compreenderem melhor os conceitos e desafios dessa área. Uma das formas mais interessantes para tal é propor o desenvolvimento de um Robô Seguidor de Linha.

O Robô Seguidor de Linha (Line Follower) é um veículo guiado automaticamente (Automated Guided Vehicle - AVG) com grande inserção na automação de processos industriais, em aplicações militares, transporte de cargas e passageiros (caminhões e carros) e até para propósitos residenciais e hospitalares, como o guiado de uma (ou várias) cadeiras de rodas robóticas. É claro que algumas aplicações demandam estratégias de controle mais sofisticadas, incluindo desvio de obstáculos, navegação de alto nível e medidas robustas de segurança. A arquitetura mais simples deste tipo de robô baseia-se em módulos infravermelho (LED IR + fotodiodo) para distinção entre uma região não reflexiva e outra reflexiva, como seria o caso de uma linha preta em um fundo branco (ou ao contrário). Sensores indutivos para seguimento de caminhos metálicos também podem ser utilizados. Geralmente este tipo de robô é um dos primeiros modelos adotados por estudantes e hobbistas. Inclusive, o desafio proposto na Olimpíada Brasileira de Robótica para crianças e jovens emprega um robô baseado em seguimento de linha.

\section{A OLIMPÍADA BRASILEIRA DE ROBÓTICA E UM BREVE HISTÓRICO DA OBR-ES}

A OBR ocorre desde 2007, e, atualmente, é considerado o maior evento de robótica da América Latina e classifica equipes para a RoboCup, maior evento de robótica do mundo. No ano de 2019, teve mais de 204 mil participantes representando todos os estados brasileiros, 
com mais de 5000 equipes competindo na modalidade prática no país. A olimpíada é dividida em duas modalidades: teórica e prática (OBR, 2020B).

A etapa prática propõe a simulação de um ambiente de desastre/desmoronamento no qual as equipes devem enviar seus robôs autônomos (não podem ser teleoperados) para superar diversos obstáculos, encontrar possíveis vítimas e levá-las a um local seguro. Neste contexto, o público pode observar as equipes resolvendo problemas reais relacionados com a robótica. Assim, é uma forma de aproximar o público de conceitos das áreas de mecatrônica e programação, como sensores e atuadores, para realizar a tarefa de resgate. O desafio é impressionante e todo ano atrai novos adeptos.

Enquanto a modalidade prática da OBR provê um cenário real para avaliação dos robôs e estratégias de cada equipe, a modalidade teórica permite que os alunos testem seus conhecimentos em temas correlatos envolvendo física, matemática, programação e sensores, dentre outros. A modalidade é constituída de provas para dois diferentes níveis elaboradas a partir do conteúdo descrito por professores e pesquisadores de várias instituições nos níveis do ensino básico, posto no Manual de Estudos da Modalidade Teórica (OBR, 2020A). Para o Ensino Médio/Técnico, a prova teórica da OBR é realizada em duas etapas, sendo a primeira local, nas próprias escolas dos alunos e a segunda etapa ocorre nas sedes regionais, como visto na Figura 1. No Ensino Fundamental há apenas uma fase. Para os alunos que apresentam melhor desempenho a nível nacional, são atribuídas medalhas de ouro, prata e bronze e de mérito.

Figura 1: $2^{\mathrm{a}}$ Fase da OBR-ES (modalidade Teórica), sediada na Ufes. 2018

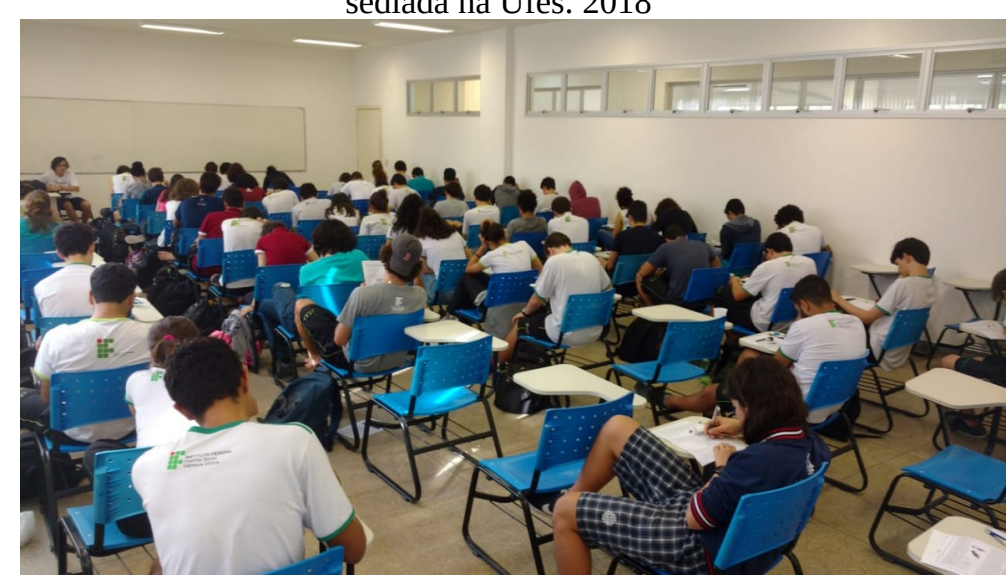

Fonte: de autoria própria.

A OBR procura, ainda, incentivar o Movimento Maker, um movimento que promove a criatividade e engenhosidade para resolver problemas de limitação, seja de materiais disponíveis, tempo ou qualquer outro que venham a aparentar impedimento do desenvolvimento de um certo projeto ou de uma etapa dele. A ideia do Movimento Maker é utilizar recursos mais acessíveis e práticos para substituir soluções que se apresentam, mais classicamente, com recursos muito mais caros ou conhecimentos muito mais complexos que os que a pessoa possui condições para implementar.

Para incentivar tal processo, a OBR possui a avaliação e premiação de categorias extras, onde são avaliados a criatividade das soluções dos alunos, seja no uso de componentes mais acessíveis ou em apresentar uma solução mais eficiente que a tradicional para a programação do robô.

A realização da Olimpíada Brasileira de Robótica - Etapa Estadual traz a oportunidade das escolas que adotam a Robótica Educacional apresentarem os trabalhos que vêm 
desenvolvendo em conjunto com seus alunos e também para troca de experiências entre os participantes (alunos da rede privada e pública) com projetos em diferentes níveis. Além disso, o diálogo e a orientação por parte do corpo técnico da competição, formado em sua maioria, por alunos da universidade que trabalham com robótica, propicia uma aproximação entre a educação básica e o ensino superior. Neste contexto, há um grande estímulo ao desenvolvimento de projetos inovadores nas áreas de ciência e tecnologia à medida que os projetos desenvolvidos pelos estudantes são reconhecidos por um corpo qualificado de jurados. Para as escolas nas quais a robótica educacional ainda não é utilizada, o evento oferece oportunidade de acesso a uma tecnologia de ponta voltada para educação.

O estado do Espírito Santo vem se destacando na área de Robótica Educacional desde 2008, quando a equipe vencedora na etapa estadual da OBR venceu também a etapa nacional e representou o Brasil na mais importante competição Mundial de Robôs: a RoboCup, realizada na China. Em 2009, novamente tivemos uma equipe do ES representando o Brasil na RoboCup na Áustria. Em 2010, mais uma vez, a equipe do ES representou o Brasil na RoboCup em Cingapura. Em 2011 e 2012, tivemos uma equipe capixaba na RoboCup da Turquia e do México, respectivamente. Em 2014 tivemos equipes capixabas nas modalidades da competição mundial de robótica - RoboCup, realizada em João Pessoa - Paraíba. Com esses resultados, o ES tem se destacado a nível nacional e internacional como um estado onde a inovação tecnológica tem sido incentivada nas escolas, e suas equipes reconhecidas e respeitadas pelos demais estados brasileiros.

\section{RESULTADOS}

Pelo relato do Professor André Ferreira, um dos coordenadores da etapa estadual do Espírito Santo, sobre a OBR 2018, podemos ver a importância desta iniciativa para as crianças e adolescentes capixabas. Ele nota: "O aspecto que nos motiva e nos impele a retornar no ano seguinte é justamente o empenho e o entusiasmo desses jovens competidores que falam dos seus robôs com tanto orgulho, como se fossem foguetes a serem enviados a outros planetas. Não tenho dúvida de que estamos deixando como legado para estas crianças e jovens o gosto pela ciência e tecnologia e, a médio e longo prazo, pessoas mais bem preparadas para os desafios profissionais, pessoas que modificarão o seu entorno na sociedade (efeito multiplicador) e que realmente farão a diferença para o país. Certamente continuarão gostando de futebol, mas agora, futebol de robôs.”

O público que participa da Olimpíada Brasileira de Robótica (modalidade prática) envolve alunos, parentes, amigos, professores e todos aqueles que têm interesse e/ou curiosidade pela robótica, direta ou indiretamente. A grande quantidade de pessoas que são mobilizadas durante a OBR na modalidade prática da estadual capixaba pode ser evidenciada na Figura 2. Dessa forma, a OBR é de grande importância, pois propicia o despertar do interesse de alunos tão cedo quanto no ensino fundamental e também no ensino médio/técnico pelo campo da robótica, provendo motivação para a realização das disciplinas de exatas/tecnológicas, que são de extrema importância para o desenvolvimento acadêmico/social do aluno e para a educação e economia de um país. 
Figura 2: Foto da OBR-ES, realização da etapa prática. 2019

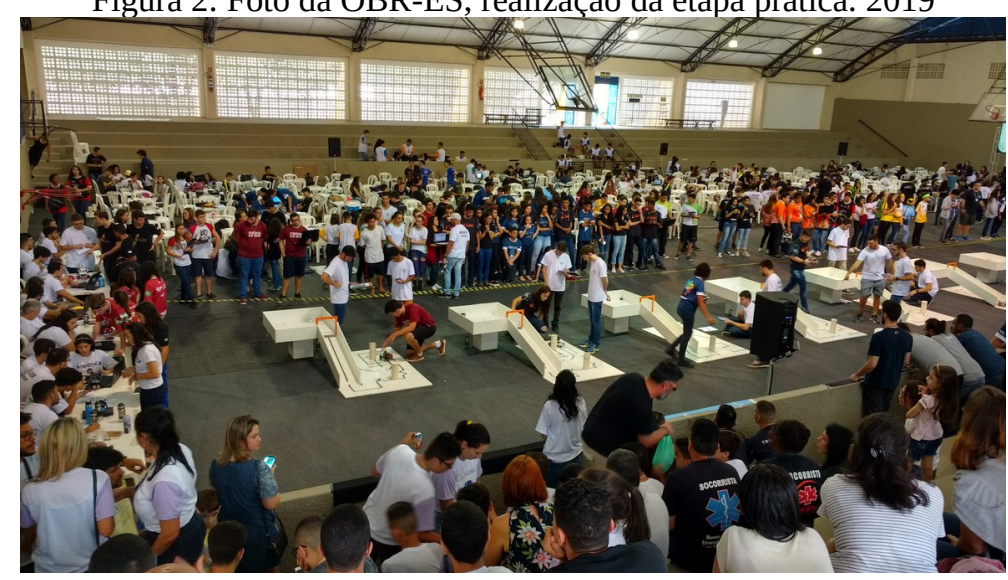

Fonte: de autoria própria.

Como um dos grandes indicativos do sucesso da etapa estadual do Espírito Santo, temos o aumento do número de equipes inscritas durante os últimos anos, visto na Tabela 1 , demonstrando uma boa aceitação do evento. No ano de 2014, havia 12 equipes de ensino fundamental e 23 de médio/técnico, já em 2017, havia 15 de ensino fundamental e 32 de médio/técnico. Em 2018, das 25 equipes inscritas do ensino fundamental, 20 participaram, e do ensino médio, compareceram 49 das 70 equipes inscritas. Por fim, o crescimento de equipes inscritas se torna ainda mais evidente no ano de 2019, onde das 56 equipes de ensino fundamental inscritas, 43 equipes participaram, e 62 das 80 equipes inscritas do ensino médio e técnico.

Tabela 1 - Número de equipes que participaram da OBR-ES nos anos de 2014 e de 2017 até 2019.

\begin{tabular}{c|c|c|}
\hline Ano & Ensino Fundamental & Ensino Médio/Técnico \\
\hline 2014 & 12 & 23 \\
\hline 2017 & 15 & 32 \\
\hline 2018 & 20 & 49 \\
\hline 2019 & 43 & 62 \\
\hline
\end{tabular}

Fonte: de autoria própria.

Um dos pontos mais notáveis da OBR é sua inclusão independente de gênero. A competição tornou-se um ambiente onde é possível notar a aptidão e interesse de todas as crianças, como é visto na Figura 3, inclusive as meninas, para as áreas de exatas como robótica, eletrônica, mecânica e computação, desconstruindo nas crianças que participam os preconceitos perpetuados historicamente relacionados a esse aspecto nas áreas associadas à tecnologia (LASTRES, et al., 2004). Os números da OBR de 2018 (MUNDO ROBÓTICA, 2018), como podem ser vistos na Figura 4, de $45 \%$ de participação feminina mostram que a noção perpetuada na sociedade que os meninos possuem maior tendência natural de interesse nas áreas das engenharias que as meninas é falsa, uma vez que quando as crianças podem demonstrar seus verdadeiros interesses naturais sem pressão de adequação aos padrões de gênero, o número de meninas que se apresentaram é quase tanto quanto de meninos. 
Figura 3: Foto mostrando inclusão de meninas e meninos na OBR de 2018.

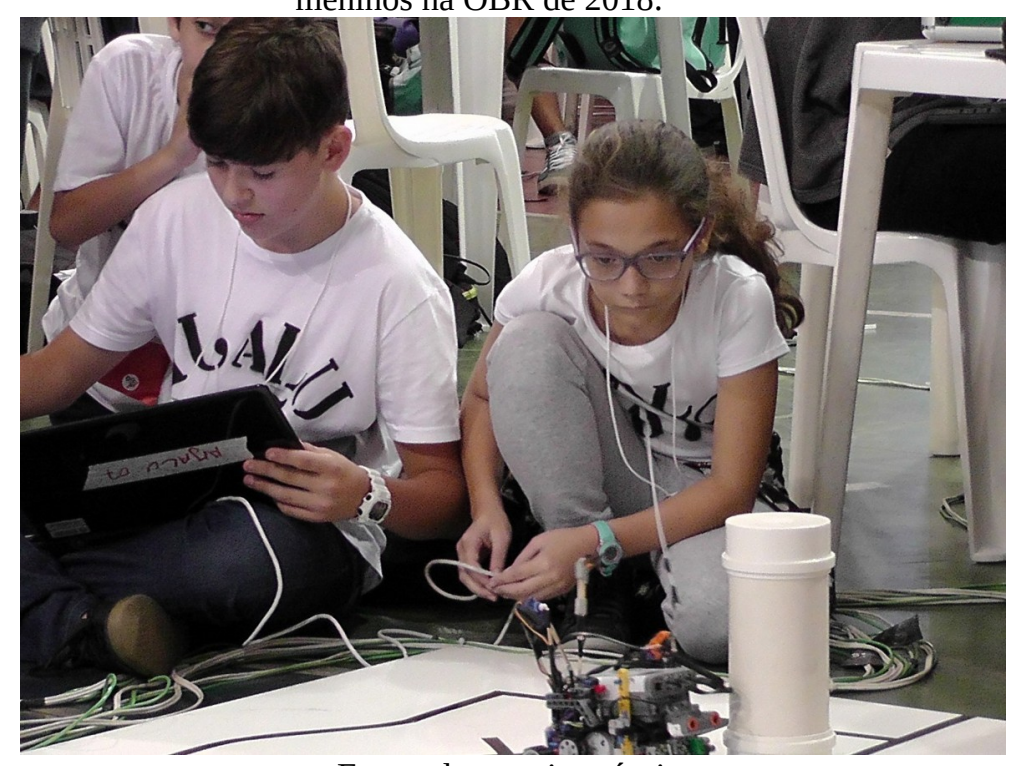

Fonte: de autoria própria.

Figura 4: Gráfico mostrando a porcentagem de inscrições de meninas e meninos na OBR de 2018.

\section{TODOS PODEM PARTICIPAR}

Homens e Mulheres, meninos e meninas aprendem e se divertem durante a OBR, em um espaço democrático e desafiador para ambos os sexos!

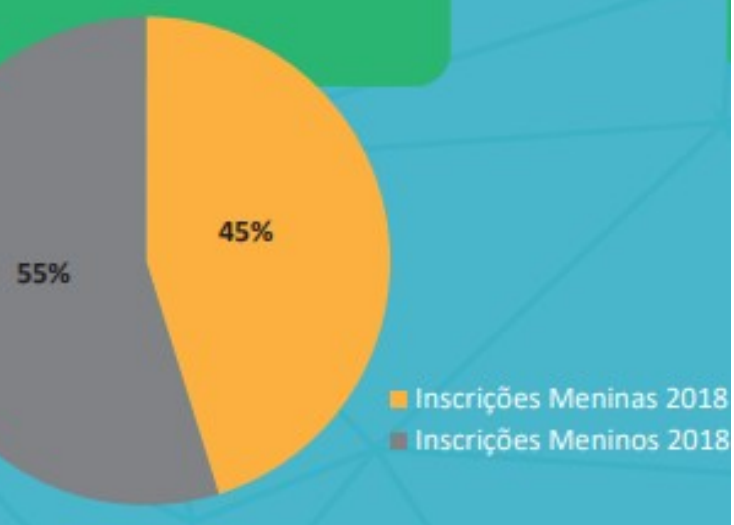

Fonte: Mundo Robótica, São Carlos: Universidade Federal de São Carlos, ano 5, n. 13, 2018. 
Por fim, é possível perceber a difusão de participantes dos mais diversos níveis acadêmicos, conforme descrito anteriormente: tanto alunos do ensino básico quanto do ensino superior (que constituem a maioria do corpo de avaliação) compartilham espaço, conhecimentos e experiências, sendo um fator motivacional enorme aos jovens que pretendem seguir nessa área. Essa aproximação propiciará, futuramente, um crescimento ainda maior do nível da robótica no estado, elevando cada vez mais o nível dos projetos realizados e os resultados obtidos pelas equipes que participam de torneios nacionais e internacionais.

\section{CONCLUSÃO}

Portanto, considerando o exposto ao longo do artigo, é natural concluir que é imprescindível o incentivo contínuo aos eventos realizados, dado que eles agem de maneira a democratizar cada vez mais o acesso à robótica por seções da sociedade essenciais e, por consequência direta, elevam o nível dos alunos ingressantes nos cursos superiores de engenharia, um grande problema para novos graduandos atualmente. Além disso, o contato direto entre competidores de diferentes níveis propicia a troca de experiências e a motivação, favorecendo a projeção da robótica capixaba no cenário nacional e até internacional. Apesar do apoio aos eventos relacionados ser um investimento de médio a longo prazo, o impacto do retorno obtido é imensurável para a sociedade como um todo. O desenvolvimento tecnológico avança a passos largos, e a posição do engenheiro capixaba nessa nova revolução propiciada pela robótica é vantajosa graças a eventos como a OBR, que promove o avanço social e intelectual da sociedade como um todo.

\section{Agradecimentos}

A organização da OBR-ES agradece à FAPES pelo apoio financeiro ao evento, possibilitando sua realização. Esta agradece, ainda, ao SESI-ES pelo apoio e parceria durante todo o processo de organização, não apenas de forma financeira, mas cedendo espaço físico, materiais e recursos humanos. Para finalizar, agradecimentos à ProEx e ao Centro Tecnológico da Ufes, por apoiar colaborando com professores e alunos que participaram ativamente tanto da organização quanto compondo o corpo de arbitragem durante a olimpíada.

\section{REFERÊNCIAS}

BLANDO, Alessandra. Dificuldades acadêmicas que interferem na aprendizagem de estudantes universitários de engenharias e de ciências exatas: um estudo fundamentado na epistemologia genética. 2015.

DANTAS FILHO, Jerônimo Vieira. Baixo rendimento na disciplina de matemática. EDUCARevista Multidisciplinar em Educação, v. 4, n. 9, p. 98-113, 2018.

DE CAMARGO RIBEIROA, Luis Roberto. Aprendizagem baseada em problemas (PBL) na educação em engenharia. Revista de Ensino de Engenharia, v. 27, n. 2, p. 23-32, 2008.

JUNG, Seul. Experiences in developing an experimental robotics course program for undergraduate education. IEEE Transactions on Education, v. 56, n. 1, p. 129-136, 2013.

LASTRES, Helena Maria Martins et al. Gênero no sistema de ciência, tecnologia e inovação no Brasil. Gênero, v. 4, 2004. 
LOPES RIPARDO, Orlando R.; DE SOUSA OLIVEIRA, Gabrielly; BRANDÃO MENEZES, Daniel. Curso Preparatório Matemática Básica CIMENG-Uma nova proposta do ensino da matemática básica para ingressos em graduações de exatas. Atlante Cuadernos de Educación y Desarrollo, n. junio, 2020.

MORALES, Juliana. Entenda o Pisa, avaliação mundial de educação, e o resultado do Brasil. 3 dez 2019. Disponível em: https://guiadoestudante.abril.com.br/atualidades/entenda-o-pisaavaliacao-mundial-de-educacao-e-o-resultado-do-brasil/. Acessado em: 30/07/2020.

MUNDO ROBÓTICA. São Carlos: Universidade Federal de São Carlos, ano 5, n. 13, 2018.

OBR. Como organizar a aplicação da Modalidade Teórica?. Olimpíada Brasileira de Robótica. 2020. Diponível em: http://www.obr.org.br/modalidade-teorica/como-organizarum-evento-modalidade-teorica/. Acessado em: 31/07/2020.

OBR. O que é a OBR. Olimpíada Brasileira de Robótica. 2020. Diponível em: http://www.obr.org.br/o-que-e-a-obr/. Acessado em: 31/07/2020.

PADIR, T.; CHERNOVA, S. Guest Editorial Special Issue on Robotics Education. IEEE Transactions on Education, v. 56, n. 1, p. 1-2, 2013.

RODRIGUES, Andréia Lilian Lima et al. Contribuições da extensão universitária na sociedade. Caderno de Graduação-Ciências Humanas e Sociais-UNIT-SERGIPE, v. 1, n. 2, p. 141-148, 2013.

ROSARIO, João Mauricio. Automação industrial. Editora Baraúna. 2012

ZILLI, Silvana do Rocio et al. A robótica educacional no ensino fundamental: perspectivas e prática. 2004.

\title{
THE BRAZILIAN ROBOTICS OLYMPICS ON ESPÍRITO SANTO AND ITS CAPIXABA COMMUNITY TRANSFORMATION POTENTIAL
}

\begin{abstract}
This article aims the OBR (Brazilian Robotics Olympics) as a tool for changing society. First, analyzing robotics as a student help in order to better develop academic skills to improve performance in University subjects considered difficult, such as Mathematics and Physics. Therefore, is also analyzed the worth of robotics as a support to the undergraduates at Engineering. In addition, the tournament structure itself is dissected, exploiting not only the interaction between the participants but also the consequences obtained in medium and long term. The maker movement and its relationship with robotics and the event are also briefly discussed. The competition history and the results are scrutinized, by connecting the robotics events investments to the results and listing some of the State's teams achievements in international contexts.
\end{abstract}

Keywords: Robotics, PBL, Olympics. 